\title{
Impact of systemic adjuvant therapy and CYP2D6 activity on mammographic density in a cohort of tamoxifen-treated breast cancer patients
}

\author{
Linda Thorén ${ }^{1,2}$ D $\cdot$ Mikael Eriksson ${ }^{3} \cdot J_{0}$ Jonan D. Lindh ${ }^{4} \cdot$ Kamila Czene $^{3} \cdot$ Jonas Bergh $^{5} \cdot$ Erik Eliasson $^{4} \cdot$ Per Hall $^{2,3} \cdot$ \\ Sara Margolin ${ }^{1,2}$
}

Received: 20 May 2021 / Accepted: 6 September 2021 / Published online: 27 September 2021

(c) The Author(s) 2021

\begin{abstract}
Purpose Change in mammographic density has been suggested to be a proxy of tamoxifen response. We investigated the effect of additional adjuvant systemic therapy and CYP2D6 activity on MD change in a cohort of tamoxifen-treated pre- and postmenopausal breast cancer patients.

Methods Swedish breast cancer patients $(n=699)$ operated 2006-2014, genotyped for CYP2D6, having at least three months postoperative tamoxifen treatment, a baseline, and at least one follow-up digital mammogram were included in the study. Other systemic adjuvant treatment included chemotherapy, goserelin, and aromatase inhibitors. Change in MD, dense area, was assessed using the automated STRATUS method. Patients were stratified on baseline characteristics, treatments, and CYP2D6 activity (poor, intermediate, extensive, and ultrarapid). Relative density change was calculated at year 1, 2, and 5 during follow-up in relation to treatments and CYP2D6 activity.

Results Mean relative DA decreased under the follow-up period, with a more pronounced MD reduction in premenopausal patients. No significant effect of chemotherapy, aromatase inhibitors, goserelin, or CYP2D6 activity on DA change was found. DA did not revert to baseline levels after tamoxifen discontinuation.

Conclusion Our results indicate that other systemic adjuvant therapy does not further reduce MD in tamoxifen-treated breast cancer patients. We could not confirm the previously suggested association between CYP2D6 activity and MD reduction in a clinical setting with multimodality adjuvant treatment. No rebound effect on MD decline after tamoxifen discontinuation was evident.
\end{abstract}

Keywords CYP2D6 · Mammographic density · Tamoxifen · Adjuvant treatment · Breast cancer · Chemotherapy

Linda Thorén

linda.thoren@ki.se

1 Department of Clinical Science and Education at Södersjukhuset, Karolinska Institutet, Stockholm, Sweden

2 Department of Oncology, Södersjukhuset, Stockholm, Sweden

3 Department of Medical Epidemiology and Biostatistics, Karolinska Institutet, Stockholm, Sweden

4 Department of Laboratory Medicine, Clinical Pharmacology, Karolinska Institutet and Karolinska University Hospital, Stockholm, Sweden

5 Department of Oncology-Pathology, Karolinska Institutet and Breast Cancer Center, Cancer Theme, Karolinska University Hospital, Karolinska Comprehensive Cancer Center, Stockholm, Sweden

\section{Introduction}

Postoperative tamoxifen treatment for 5 years substantially reduces the risk for recurrence as well as breast cancer mortality. Women with high risk of recurrence are currently recommended extended treatment for 10 years [1], 2. Up to $40 \%$ of patients with early ER-positive breast cancer will, however, relapse within 20 years suggesting a wide variability in the response to adjuvant tamoxifen treatment [3]. Currently, there are no means of ascertaining the adjuvant effect of tamoxifen. Markers of early response to tamoxifen therapy are thus needed.

Tamoxifen, a selective estrogen-receptor modulator (SERM), inhibits estrogen-stimulated proliferation in ERpositive breast cancer by competitively binding to the ER [4]. Tamoxifen is a weak antiestrogen and requires hepatic 
biotransformation to more potent metabolites-most importantly endoxifen - by hepatic cytochrome P450 2D6 (CYP2D6) [5]. The CYP2D6 gene is highly polymorphic with more than 100 known allelic variants [6]. Each allele has been given an activity score (AS) ranging from $0-1$. The sum of the AS values assigned to each allele are used to translate an individual's CYP2D6 genotype into a phenotype [7].

Patients carrying a poor metabolizer [PM] genotype, approximately 5\% of the European population [8], benefit less from tamoxifen treatment compared to intermediate [IM], extensive [EM], and ultrarapid [UM] metabolizers [9-12]. The clinical impact of CYP2D6 is, however, still controversial partly due to contradictory results from retrospective studies [13-15].

Change in mammographic density (MD) has been suggested as an early marker for tamoxifen response, indicating that women whose MD declined during tamoxifen therapy have a better prognosis than patients without a density decrease [16-23]. It has been hypothesized that the decline in MD may reflect levels of active tamoxifen metabolites. CYP2D6 status has been shown to influence the reduction in mammographic density during tamoxifen treatment in postmenopausal women [24].

Previous studies on breast density change have, however, mainly been conducted in patients receiving tamoxifen alone, as systemic treatment, a situation which is rarely seen in clinical practice, except in premenopausal patients with a low risk for recurrence. Patients at high risk of recurrence also generally receive anthracycline and/or taxane-based therapies, anti-Her2 treatments, and sometimes a switch between tamoxifen and aromatase inhibitors [25-27]. The knowledge of how systemic adjuvant therapy other than tamoxifen might affect MD change in breast cancer patients is limited [28]. The association between CYP2D6 activity and MD change in tamoxifen-treated breast cancer patients also receiving multimodality treatment is insufficiently studied [24].

Our aim was to investigate the effect of CYP2D6 activity and additional systemic treatment, including chemotherapy, GnRH-analogs and switch to aromatase inhibitors, on MD change, in a cohort of tamoxifen-treated pre- and postmenopausal breast cancer patients.

\section{Patients and methods}

\section{Patients}

Since 2006, DNA from peripheral blood has been collected and biobanked from newly diagnosed breast cancer patients at the Karolinska University Hospital and at Södersjukhuset, Stockholm, Sweden. From the national breast cancer registry
(INCA), we identified 1256 breast cancer patients undergoing surgery January 2006-January 2014 in Stockholm. All of these patients had available DNA extracted from peripheral blood for CYP2D6 genotyping, were ER positive and initiated adjuvant tamoxifen treatment at the Departments of Oncology, Karolinska University Hospital or Södersjukhuset.

Inclusion criteria were having CYP2D6 genotyped, at least three months of adjuvant tamoxifen treatment according to patient records and a digital baseline mammogram followed by at least one digital follow-up mammogram. The baseline mammogram was defined as the latest available non-diagnostic mammogram prior to diagnosis of breast cancer. Date of follow-up mammogram should have been at least 3 months after diagnosis.

Patients were excluded if they did not receive tamoxifen upfront as adjuvant endocrine therapy, if they had been previously operated because of a contralateral breast cancer or were diagnosed with bilateral breast cancer at baseline. Patients who developed a contra lateral breast cancer or underwent contra lateral/ bilateral prophylactic mastectomy after study baseline contributed to the study up to the time of diagnosis or surgery. A detailed description of the selection of the study population is depicted in Online resource 1.

Information on menopausal status, tumor characteristics, body mass index (BMI), concomitant medication, systemic breast cancer treatment, compliance, side effects, and follow-up was obtained from medical records. Patients were considered postmenopausal one year after their last menstrual period or after bilateral oophorectomy. Patients with unknown menopausal status were defined as postmenopausal if age at diagnosis was $>55$ years. If there was unequivocal information in the record that the patient had stopped taking tamoxifen during the first five years, she was classified as non-compliant.

\section{Mammographic density measurement}

Digital full-field mammograms from the mediolateraloblique (MLO) breast view were retrieved up until January 2018. Mammographic dense area (DA), dense area/total breast area in $\mathrm{cm}^{2}$ of the left and right breasts, was measured using the fully automated STRATUS method. Before measurement and comparison were performed, images of the same breast were aligned to reduce technical differences between images, a method described previously [29]. The aligned density measurements from the image contralateral to the tumor from MLO view were averaged to form a single measurement for each examination. Mammographic density was measured at baseline and follow-up.

As we lacked information on BMI at follow-up, changes in the absolute DA rather than changes in PMD were chosen. PMD is highly, inversely correlated with BMI, whereas DA 
has been shown to be only weakly associated with BMI [30, 31].

\section{Genotyping of CYP2D6}

The biobanked DNA was stored frozen at $-80{ }^{\circ} \mathrm{C}$ and transported frozen for analysis. Analysis of CYP2D6 variant alleles was performed using TaqMan-based real-time PCR assays rigorously validated and implemented for routine clinical pharmacogenetic analyses at Diakonhjemmet Hospital in Oslo, Norway. The CYP2D6 genotyping panel included the non-coding ("null") variants CYP2D6*3 (rs35742686), CYP2D6 * 4 (rs3892097), CYP2D6 * 5 (gene deletion), and CYP2D6 * 6 (rs5030655), the decreasedfunction variants $C Y P 2 D 6 * 9$ (rs5030656), CYP2D6 * 10 (rs 1065852), and CYP2D6 * 41 (rs28371725) and the increased-function variant $C Y P 2 D 6 * 1 X N$. Without detection of any of the above variant alleles, the genotype was defined as CYP2D $6 * 1 / * 1$. In the copy number analysis, samples with gene CYP2D6 gene deletions were identified and interpreted as $C Y P 2 D 6 * 5$, whereas the allele multiplication/duplication analysis could not distinguish between $C Y P 2 D 6 * 1, C Y P 2 D 6 * 4$ and $C Y P 2 D 6 * 41$, leading to a simplified but commonly applied interpretation that the extra allele was fully active [9]. With regard to the latter limitation, an inconclusive genotyping result with regard to predicted activity (i.e., CYP2D6 $* 1 / * 4, C Y P 2 D 6 * 1 / * 41$ or $C Y P 2 D 6 * 4 / * 41$ in combination with $\mathrm{CNA}=3$ or 4 ) would lead to study exclusion.

\section{Predicted CYP2D6 activity}

Each CYP2D6 allele was given an activity score (AS), according to The Clinical Pharmacogenetics Implementation Consortium (CPIC) guidelines. The sum of the AS values assigned to each allele was used to classify the patients into predicted CYP2D6 phenotypes; poor metabolizers, PM, $(\mathrm{AS}=0)$, intermediate metabolizers, $\mathrm{IM},(\mathrm{AS}=0.5$ or 1.0$)$, extensive metabolizers, EM, (AS =1.5-2.0), or ultrarapid metabolizers, UM, (AS > 2.0) [32]. An alternative AS, categorizing patients with CYP2D6 $* 3 / * 4 / * 5 / * 6$ in combination with CYP2D6 $* 9 / * 10 / * 41$ as PM was also used [7, 33].

\section{Statistical analysis}

Differences in characteristics of the included and not included women were estimated using Student's t test on the continuous variables age, BMI, age at menopause, and treatment duration, and using Fisher's exact test for the dichotomous variables menopausal status, use of tamoxifen and other endocrine treatment, chemotherapy, and CYP2D6 activity.
Baseline average mammographic density was analyzed using Local Polynomial Regression Fitting (LOESS) to investigate the trend across age [34].The fitted curve was plotted across age in relation to healthy women from the external KARMA cohort, including more than 70000 women attending mammography screening between 2011 and 2013 in Sweden and from whom digital mammograms were stored [29].

Average density decreases after initiation of tamoxifen treatment was plotted in pre- and postmenopausal women from the time of baseline until the end of follow-up, using Local Polynomial Regression Fitting (LOESS) with 95\% confidence intervals. The study participants contributed with measures of mammographic density change till the end of follow-up or till time of medication discontinuation.

Relative density change was calculated for each follow-up mammogram as the follow-up density measurement minus the baseline density measurement, divided by the baseline density measurement [35]. Mean relative dense area decrease at year 1,2, and 5 during follow-up was estimated using non-linear $b$-spline regression. Ninety-five percent confidence intervals were estimated using 1000 bootstrappings. Analyses were stratified by received treatments and CYP2D6 activities. The study participants contributed with measures of mammographic density change till the end of follow-up or till time of medication discontinuation. P-trends for CYP2D6 activities were estimated using linear regression in postmenopausal women at year 5 .

Among women who discontinued tamoxifen, average density change was analyzed in the range 5 years prior to discontinuation until 5 years after discontinuation using nonlinear b-spline regression [36]. The fitted model was plotted with 95\% confidence intervals for pre- and postmenopausal women. Mammograms were performed yearly according to clinical routine during follow-up regardless whether the patient had discontinued the endocrine treatment or not. The mammograms closest to discontinuation and yearly mammograms thereafter were used in the analysis.

All statistical analyses were performed using SAS 9.4. All statistical tests were two sided, and statistical significance was set to an alpha 0.05 .

\section{Results}

In all, 699 women were included in the study. The majority $(82 \%)$ of the patients received tamoxifen as their only adjuvant endocrine treatment during a mean treatment period of 4.1 years. Twelve percent of the patients switched from tamoxifen to an aromatase inhibitor, $6 \%$ were treated with a combination of tamoxifen and goserelin, and one percent received a combination of goserelin and aromatase inhibitor after tamoxifen. Notably, 
$26 \%$ of the patients had received neoadjuvant or adjuvant chemotherapy (56\% of the premenopausal and $4 \%$ of the postmenopausal patients), consisting mostly of 6 courses of cyclophosphamide, epirubicin plus Fluorouracil $(5-F U)$, with or without docetaxel. Five percent of the patients were treated with trastuzumab. Forty two percent of the patients in the study cohort were premenopausal.

Mean time between breast cancer diagnosis and first follow-up mammogram was 1.4 years. The corresponding figure between breast cancer diagnosis and last mammogram was 4.9 years (Table 1). Mammograms were available for 358 patients at year 1 of follow-up, 429 at year 2, 482 at year 3, 448 at year 4 and for 381 patients at year 5 . 251 patients had available mammograms after more than 5 years of follow-up. According to information in medical records, $4 \%$ of the patients had, at some point during tamoxifen treatment, concomitant treatment with a clinically relevant CYP2D6 inhibitor. Four patients with undetermined CYP2D6 genotype were excluded. CYP2D6 metabolizer status was stratified according to CPIC guidelines to $7 \% \mathrm{PM}$, $36 \% \mathrm{IM}, 54 \% \mathrm{EM}$, and $3 \% \mathrm{UM}$.

To identify a possible selection bias in our study sample, the excluded women from the full breast cancer patient population were compared with patients participating in the study. No significant differences were found regarding age, BMI, menopausal status, tumor size, ER/PR-status, Her2-status, positive lymph nodes, CYP2D6 status, or use of aromatase inhibitors. Patients included in the study had tumors with lower grade and proliferation and were more frequently treated with tamoxifen only as endocrine treatment, compared to patients not included in the study ( 82 vs $69 \%, p<0.01$ ). Study patients were concordantly less frequently treated with tamoxifen in combination with goserelin $(6$ vs $15 \%, p<0.01)$ and had a longer treatment duration of tamoxifen (4.1 years, SD 1.6, vs 3.8 years SD2.0, $p<0.01$ ) (Online resource 2).

Mean absolute DA at baseline was $35.5 \mathrm{~cm}^{2}(\mathrm{SD}$ 27.7). The average density at baseline was $50 \mathrm{~cm}^{2}$ among

Table 1 Baseline characteristics of study participants and assigned treatments

\begin{tabular}{|c|c|c|c|}
\hline Characteristics & Premenopausal & Postmenopausal & Whole cohort \\
\hline$N(\%)$ & $293(58)$ & $406(42)$ & $699(100)$ \\
\hline Age at breast cancer diagnosis mean, range, (SD) & $46.2,27-55(4.9)$ & $64.0,47-82(6.6)$ & $56.5,27-82(10.6)$ \\
\hline Body Mass Index (BMI) at baseline, $\mathrm{kg} / \mathrm{m}^{2}$, mean, (SD) & $25.2(4.6)$ & $26.1(4.5)$ & $25.7(4.6)$ \\
\hline Menopausal age, years, mean (SD) & - & $50.0(2.7)$ & $50.0(2.7)$ \\
\hline Age at baseline mammogram, mean, years (SD) & $46.0(4.8)$ & $63.8(1.2)$ & $56.3(10.6)$ \\
\hline $\begin{array}{l}\text { Time from baseline mammogram to first follow-up mammogram, median, } \\
\text { years (IQR) }\end{array}$ & $1.5(1.6)$ & $1.4(1.3)$ & $1.4(1.5)$ \\
\hline Mammographic dense area $\left(\mathrm{cm}^{2}\right)$ of fibro-glandular tissue, mean (SD) & $47.9(29.5)$ & $26.8(22.6)$ & $35.5(27.7)$ \\
\hline Estrogen receptor positive, $N(\%)^{\mathrm{a}}$ & $293(100)$ & $406(100)$ & $699(100)$ \\
\hline Progesterone receptor positive, $N(\%)^{\mathrm{b}}$ & $290(99)$ & $402(99)$ & $692(99)$ \\
\hline Chemotherapy, $N(\%)$ & $164(56)$ & $17(4)$ & $181(26)$ \\
\hline \multicolumn{4}{|l|}{ Endocrine treatment } \\
\hline Tamoxifen only, $N(\%)$ & $228(78)$ & $346(85)$ & $574(82)$ \\
\hline Tamoxifen and goserelin, $N(\%)$ & $41(14)$ & - & $41(6)$ \\
\hline Tamoxifen and aromatase inhibitor, $N(\%)$ & $24(8)$ & $60(15)$ & $84(12)$ \\
\hline Tamoxifen, goserelin, and aromatase inhibitor, $N(\%)$ & $6(2)$ & - & 1 \\
\hline Tamoxifen treatment years, mean (SD) & $4.3(1.7)$ & $4.0(1.5)$ & $4.1(1.6)$ \\
\hline \multicolumn{4}{|l|}{ CYP2D6 activity according to CPIC's guidelines[32], $n(\%)$} \\
\hline CYP2D6 Poor Metabolizers (PM) & $25(8.5)$ & $23(5.7)$ & $48(6.9)$ \\
\hline CYP2D6 Intermediate Metabolizers (IM) & $107(36.5)$ & $222(54.7)$ & $252(36.0)$ \\
\hline CYP2D6 Extensive Metabolizers (EM) & $153(52.2)$ & $145(35.7)$ & $375(53.6)$ \\
\hline CYP2D6 Ultrarapid Metabolizers (UM) & $8(2.7)$ & $16(3.9)$ & $24(3.4)$ \\
\hline Follow-up time to last mammography, mean, years (SD) & $4.9(1.8)$ & $4.9(1.7)$ & $4.9(1.7)$ \\
\hline
\end{tabular}

Percentages may not add up to 100 due to rounding

Abbreviations: $S D$ Standard Deviation, IQR Inter Quartile Range, CYP2D6 Cytochrome P450 2D6, CPIC The Clinical Pharmacogenetics Implementation Consortium

${ }^{\text {a }}$ Tumors were considered Estrogen receptor (ER) positive and Progesterone receptor (PR) positive if $\geq 10 \%$ of the cells stained positive for the receptor by IHC on the resected tumor specimen and/ or pre-operative biopsy. 1 patient was ER negative, but PR positive and was, thus, defined as ER positive. For 3 patients, ER-status was missing. They were treated as ER positive

${ }^{\mathrm{b}}$ For 7 patients, PR-status was missing 
40-year-old women and decreased to approximately $25 \mathrm{~cm}^{2}$ for women at the age of 74 , with a clear decline during the menopausal transition (age 45-55). Mean DA at baseline was higher across age among study participants compared to healthy women in the external KARMA cohort (Fig. 1).

During the first year, DA change was more pronounced in the premenopausal group compared to the postmenopausal women (Fig. 2), a difference that disappeared beyond one year after diagnosis.

Mean relative density change at year one of follow-up was -18.1 (CI-22.9, -13.9) in the whole cohort, -22.2 (CI-26.6, -16.6) and -15.9 (CI-22.7, -9.0) in the pre- and postmenopausal subgroups, respectively. In the patients with tamoxifen monotherapy, the corresponding mean relative density change was -18.2 (CI-23.2, -14.0) in the whole group, -23.0 (CI-26.2, -19.0) among the premenopausal patients and -15.0 (CI-22.2, -7.4) in the postmenopausal cohort. As expected, the relative density change increased over time. The density decrease in the chemotherapy-treated premenopausal group was similar to patients treated with tamoxifen only. Density decrease had similar effect estimates in chemo-treated pre- and postmenopausal patients at year 1 and 2. In the postmenopausal chemotherapy-treated subgroup, consisting of 17 patients, a MD decrease was, however, seen compared to postmenopausal women treated with tamoxifen only.

No additional effect of aromatase inhibitors, goserelin, or CYP2D6 activity on DA decrease was observed. We did observe what appears to be a trend of density reduction with higher CYP2D6 activity scores at year 5 among postmenopausal patients who received tamoxifen treatment only and for all patients who also received chemotherapy, $p=0.05$ (Table 2), (Online resource 3).

In all, 192 patients (27\%) discontinued tamoxifen within 5 years of treatment start. No rebound in breast density after tamoxifen discontinuation was evident in the 29 of the premenopausal women and 60 of the postmenopausal women for whom mammograms after tamoxifen cessation were available (Fig. 3). The premenopausal women were on average 51.9 (SD 4.8) years at tamoxifen discontinuation and had 4.9 (SD 2.6) years of follow-up. The mean age for the postmenopausal women at tamoxifen discontinuation was 67.4 years (SD 6.8) and their mean follow-up was 3.9 years (SD 1.8). No further density decrease was seen in women discontinuing tamoxifen and switching to aromatase inhibitors or goserelin (data not shown).

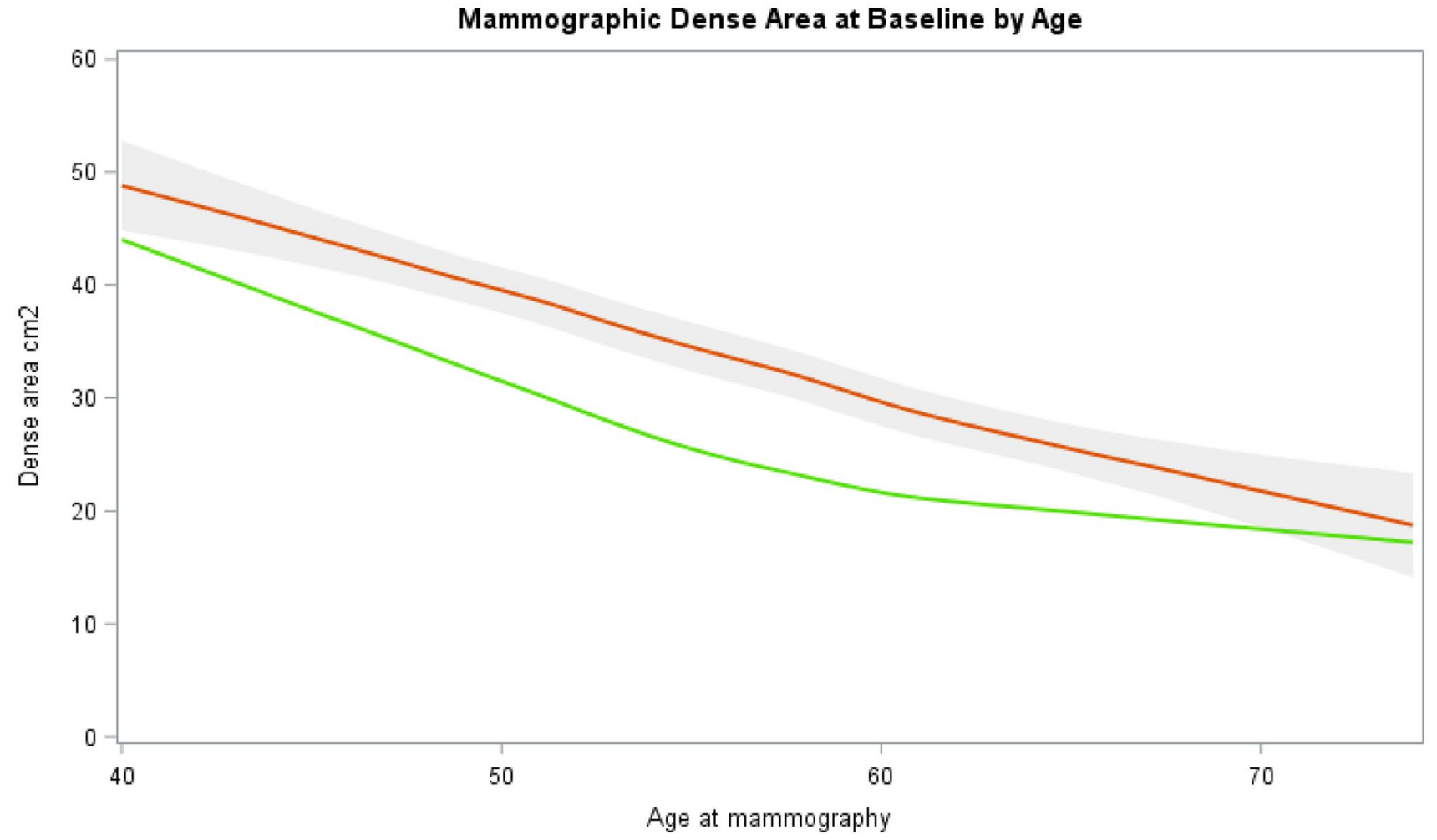

Fig. 1 Mammographic dense area at baseline by age in breast cancer cases in tamoxifen cohort in relation to healthy women from the KARMA external cohort. Baseline average mammographic density was analyzed using Local Polynomial Regression Fitting (LOESS) to investigate the trend across age. The fitted curve was plotted across age in relation to healthy women from the external KARMA cohort (27). Red curve shows the breast cancer cases in the tamoxifentreated cohort. Gray area shows the $95 \%$ confidence interval. Green curve shows average density across age in the same age range for women in the KARMA cohort 


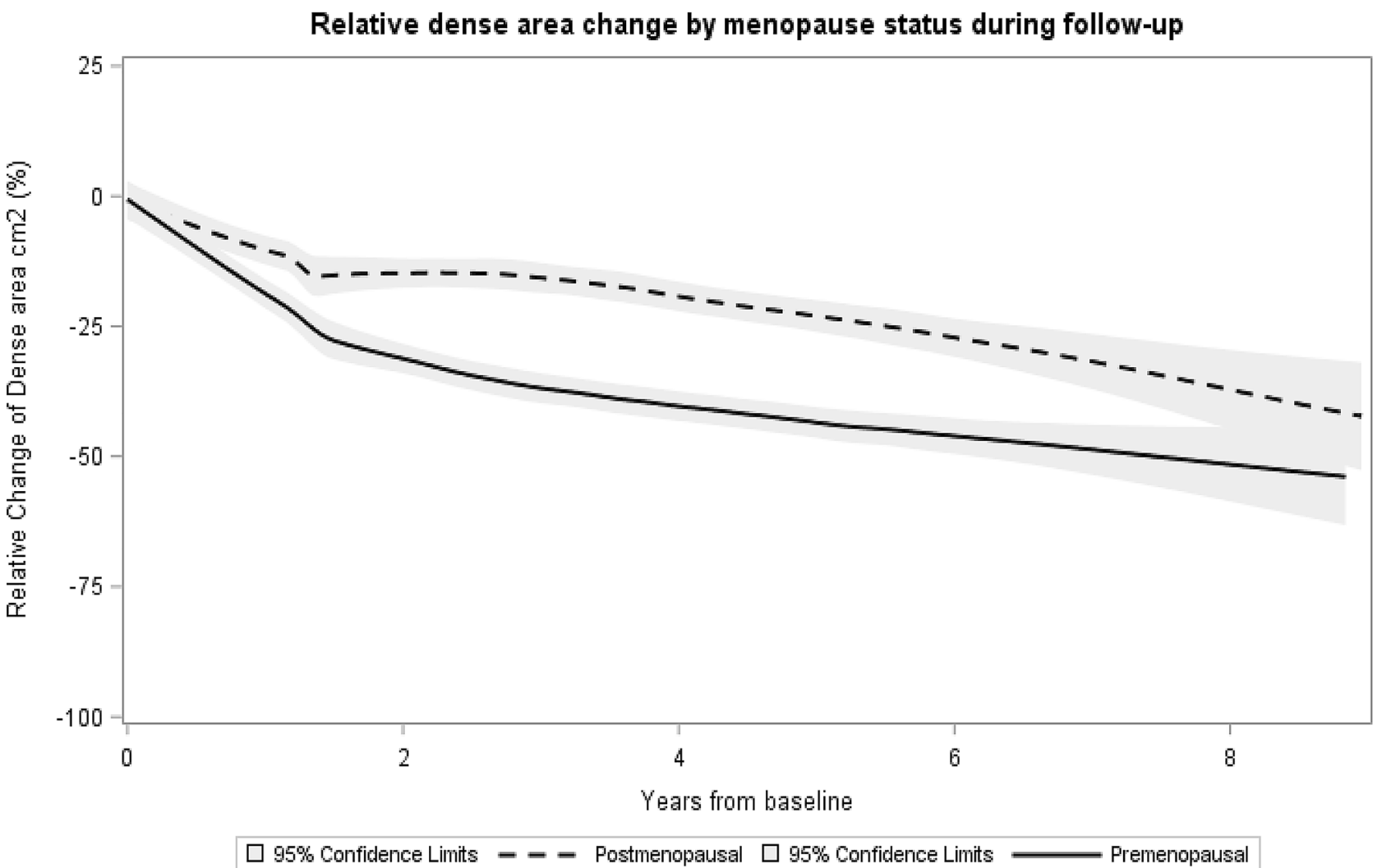

Fig. 2 Relative density change of dense area at baseline until the end of follow-up in pre- and postmenopausal patients. Relative density change was calculated for each follow-up mammogram as the followup density measurement minus the baseline density measurement, in turn divided by the baseline density measurement. Average density decrease after initiation of tamoxifen treatment was plotted in pre-

\section{Discussion}

In this cohort of tamoxifen-treated breast cancer patients neither aromatase inhibitors, goserelin nor chemotherapy were associated with significant additional mammographic density change. A previously reported effect of CYP2D6 activity on density decrease was not possible to confirm in the present study. Furthermore, stopping tamoxifen early did not, in our material, lead to a subsequent increase to baseline MD levels.

Higher breast density is a strong risk factor for breast cancer [20,37], and MD at baseline was indeed higher among our study participants than in healthy women compared by age (Fig. 1) [29]. The baseline density was comparable to the breast cancer cohort by Nyante et al. with a similar age span [38]. The decline in mammographic density was greatest during the menopausal transition, supporting an underlying hormonal mechanism for breast density change.

Several previous studies, including a recent prevention trial [35], have shown promising results using reduction and postmenopausal women from the time of baseline until the end of follow-up, using Local Polynomial Regression Fitting (LOESS). Ninety-five percent confidence intervals were estimated using boot strapping. The study participants contributed with measures of mammographic density change till the end of follow-up or till time of medication discontinuation

in mammographic density as an early marker of adjuvant tamoxifen response. This could be important additional information when prescribing and choosing long-term adjuvant endocrine therapy, with substantial side effects, to breast cancer patients. These studies have, however, mainly been conducted in patient cohorts treated with tamoxifen alone, as systemic treatment. In the modern clinical reality, many patients receive multimodality treatment.

Most studies evaluating density change associated with adjuvant tamoxifen have used mammograms obtained around 12 to 18 months after cancer diagnosis [17]. MD assessment has, however, differed by mammogram modality and methodology (analog vs. digital mammograms, absolute vs. relative MD change and in the age span of included patients), which makes comparisons difficult. For instance, a study by $\mathrm{Li}$ et al. 2013 observed that more than $50 \%$ of the patients experienced a MD decrease of at least $20 \%$ at their 12- to 18-month mammogram [21]. In line with previous studies, the degree of MD reduction under tamoxifen treatment was more pronounced in the premenopausal group 
Table 2 Relative density change (\%) at year 1, 2, and 5 during follow-up in relation to received treatments and CYP2D6 activity

\begin{tabular}{|c|c|c|c|}
\hline & Premenopausal $^{\mathrm{a}}(\mathrm{CI}), n$ & Postmenopausal $^{\mathrm{a}}(\mathrm{CI}), n$ & Combined (CI), $n$ \\
\hline \multicolumn{4}{|l|}{ Treatment } \\
\hline \multicolumn{4}{|l|}{ Year 1} \\
\hline All tamoxifen-treated women & $-22.2(-26.6,-16.6), n=143$ & $-15.9(-22.7,-9.0), \mathrm{n}=215$ & $-18.1(-22.9,-13.9), \mathrm{n}=358$ \\
\hline Tamoxifen only subgroup ${ }^{\mathrm{b}}$ & $-23.0(-26.2,-19.0), n=114$ & $-15.0(-22.2,-7.4), n=184$ & $-18.2(-23.2,-14.0), n=298$ \\
\hline Chemotherapy subgroup & $-22.9(-28.8,-14.8), n=81$ & $-21.3(-42.0,7.7), n=9$ & $-22.6(-28.3,-14.7), \mathrm{n}=90$ \\
\hline Goserelin subgroup & $-15.8(-29.4,1.7), n=17$ & N/A & $-15.8(-29.4,1.7), n=17$ \\
\hline Aromatase inhibitor subgroup & $-25.3(-40.7,-12.2), n=14$ & $-14.2(-34.9,-0.9), n=31$ & $-19.0(-31.9,-8.7), n=45$ \\
\hline \multicolumn{4}{|l|}{ Year 2} \\
\hline All tamoxifen-treated women & $-31.8(-36.2,-27.8), n=170$ & $-13.1(-17.5,-7.6), n=259$ & $-21.1(-24.4,-16.6), n=429$ \\
\hline Tamoxifen only subgroup ${ }^{\mathrm{b}}$ & $-32.7(-37.3,-27.6) n=138$ & $-14.1(-18.3,-8.5), n=223$ & $-21.5(-24.8,-17.4), n=361$ \\
\hline Chemotherapy subgroup & $-35.1(-41.8,-29.3), n=97$ & $-35.1(-58.5,-18.9), n=11$ & $-35.8(-42.7,-29.8), \mathrm{n}=108$ \\
\hline Goserelin subgroup & $-27.7(-39.8,-16.6), n=16$ & N/A & $-27.7(-39.8,-16.6), n=16$ \\
\hline Aromatase inhibitor subgroup & $-30.9(-46.1,-19.5), n=19$ & $-10.9(-21.3,3.2), n=36$ & $-19.1(-27.0,-9.8), \mathrm{n}=55$ \\
\hline \multicolumn{4}{|l|}{ Year 5} \\
\hline All tamoxifen-treated women & $-43.6(-47.7,-38.5), n=162$ & $-24.8(-31.0,-19.7), n=219$ & $-32.4(-36.8,-28.7), n=381$ \\
\hline Tamoxifen only subgroup ${ }^{\mathrm{b}}$ & $-44.5(-48.9,-39.5), n=127$ & $-24.2(-29.7,-19.6), n=185$ & $-32.2(-37.0,-28.6), n=312$ \\
\hline Chemotherapy subgroup & $-44.6(-51.1,-33.8), n=94$ & $-35.8(-61.8,-17.4), n=12$ & $-43.2(-49.3,-33.9), n=106$ \\
\hline Goserelin subgroup & $-47.4(-59.7,-32.9), n=18$ & N/A & $-47.4(-59.7,-32.9), n=18$ \\
\hline Aromatase inhibitor subgroup & $-36.2(-49.7,-9.8), n=18$ & $-25.3(-38.9,-12.0), n=34$ & $-28.2(-37.9,-17.0), n=52$ \\
\hline \multicolumn{4}{|l|}{ CYP2D6 activity ${ }^{\mathrm{c}}$} \\
\hline \multicolumn{4}{|l|}{ Year 1} \\
\hline PM & $-24.2(-38.9,-11.2), n=10$ & $-5.6(-27.2,18.4), n=14$ & $-15.2(-28.4,-2.9), n=24$ \\
\hline IM & $-14.3(-22.7,-4.0), n=55$ & $-14.4(-29.5,-3.7), n=69$ & $-13.8(-21.1,-8.2), n=124$ \\
\hline EM & $-26.0(-34.9,-19.2), n=75$ & $-17.2(-25.6,-9.8), n=123$ & $-21.3(-28.6,-15.4), n=198$ \\
\hline $\mathrm{UM}$ & $-24.0(-50.6,8.5), n=3$ & $2.1(-45.1,58.5), n=9$ & $-2.2(-35.4,120.8), n=12$ \\
\hline \multicolumn{4}{|l|}{ Year 2} \\
\hline PM & $-35.0(-46.7,-25.2), n=12$ & $-11.1(-25.6,0.9), n=16$ & $-23.1(-33.5,-15.2), n=28$ \\
\hline IM & $-30.7(-39.8,-22.8), n=60$ & $-9.43(-16.7,0.5), n=84$ & $-18.7(-23.8,-12.9), n=144$ \\
\hline EM & $-32.6(-37.6,-27.2), n=94$ & $-16.3(-21.4,-9.7), n=149$ & $-22.5(-26.7,-17.1), n=243$ \\
\hline $\mathrm{UM}$ & $-39.9(-65.6,1.4), n=4$ & $-11.4(-41.6,14.7), n=10$ & $-19.9(-42.7,2.9), n=14$ \\
\hline \multicolumn{4}{|l|}{ Year 5} \\
\hline PM & $-52.9(-63.1,-36.2), n=11$ & $-15.0(-28.9,5.5), n=11$ & $-33.7(-43.0,-13.5), n=22$ \\
\hline IM & $-44.1(-53.2,-35.9), n=64$ & $-21.2(-30.5,-13.1), n=78$ & $-30.9(-39.1,-25.2), n=142$ \\
\hline EM & $-42.4(-47.7,-33.5), n=81$ & $-26.4(-34.9,-20.4), n=120$ & $-32.6(-38.1,-27.7), n=201$ \\
\hline $\mathrm{UM}$ & $-51.3(-73.9,-31.1), n=6$ & $-39.3(-61.5,-20.2), n=10$ & $-43.0(-57.8,-29.0), n=16$ \\
\hline \multicolumn{4}{|c|}{ CYP2D6 activity ${ }^{\mathrm{c}}$ in tamoxifen only subgroup } \\
\hline \multicolumn{4}{|c|}{ Year 1} \\
\hline PM & $-25.5(-37.8,-11.6), n=7$ & $-1.4(-24.0,60.3), n=12$ & $-13.4(-25.8,2.0), n=19$ \\
\hline IM & $-16.1(-24.4,-6.1), n=44$ & $-16.5(-33.3,-4.9), n=57$ & $-15.2(-23.8,-9.5), n=101$ \\
\hline EM & $-27.4(-36.8,-20.7), n=60$ & $-16.4(-25.2,-8.7), n=109$ & $-20.9(-27.8,-14.8), n=169$ \\
\hline $\mathrm{UM}$ & $-19.9(-58.2,13.2), n=3$ & $-6.4(-104.0,72.8), n=6$ & $-11.0(-67.8,39.9), n=9$ \\
\hline \multicolumn{4}{|l|}{ Year 2} \\
\hline PM & $-40.0(-51.3,-29.1), n=9$ & $-12.1(-28.5,4.6), n=13$ & $-24.7(-36.3,-13.6), n=22$ \\
\hline $\mathrm{IM}$ & $-29.2(-39.7,-21.4), n=52$ & $-7.6(-15.1,2.8), n=67$ & $-17.7(-22.7,-10.8), n=119$ \\
\hline $\mathrm{EM}$ & $-34.4(-40.4,-27.5), n=74$ & $-17.4(-23.6,-11.4), n=134$ & $-23.5(-28.0,-18.4), n=208$ \\
\hline $\mathrm{UM}$ & $-33.6(-59.7,19.5) n=3$ & $-14.5(-44.7,16.3), n=9$ & $-19.6(-44.6,5.5), n=12$ \\
\hline \multicolumn{4}{|l|}{ Year 5} \\
\hline PM & $-59.4(-69.4,-45.8), n=6$ & $-16.0(-32.4,8.2), n=9$ & $-35.6(-48.0,-16.1), n=15$ \\
\hline $\mathrm{IM}$ & $-42.4(-54.4,-33.6), n=50$ & $-18.9(-28.0,-9.5), n=62$ & $-28.4(-36.0,-22.5), n=112$ \\
\hline EM & $-44.6(-51.3,-37.9), n=65$ & $-27.1(-36.0,-20.1), n=105$ & $-33.5(-39.3,-28.4), n=170$ \\
\hline
\end{tabular}


Table 2 (continued)

\begin{tabular}{llll}
\hline & Premenopausal $^{\mathrm{a}}(\mathrm{CI}), n$ & Postmenopausal $^{\mathrm{a}}(\mathrm{CI}), n$ & Combined $(\mathrm{CI}), n$ \\
\hline $\mathrm{UM}$ & $-50.6(-71.7,-29.4), n=6$ & $-42.6(-65.8,-23.0), n=9$ & $-45.6(-62.9,-31.1), n=15$ \\
\hline
\end{tabular}

Mean relative dense area decrease was estimated using non-linear b-spline regression. Ninety-five percent confidence intervals were estimated using boot strapping. The study participants contributed with measures of mammographic density change till the end of follow-up or till time of medication discontinuation. P-trends for CYP2D6 activities were estimated using linear regression in postmenopausal women at year 5. The p-trend was 0.05 for the patients who received tamoxifen treatment only and 0.05 for all patients who also received chemotherapy. N/A Not applicable

Abbreviations: CI Confidence interval, CYP2D6 Cytochrome P450 2D6, CPIC The Clinical Pharmacogenetics Implementation Consortium

${ }^{a}$ Menopause status at study baseline

${ }^{\mathrm{b}}$ Subgroup with tamoxifen only and w/o chemotherapy, goserelin, aromatase inhibitor treatment

${ }^{\mathrm{C}}$ A CYP2D6 activity score (AS) according to CPIC was used to classify patients into predicted phenotypes: poor metabolizers (PM), intermediate metabolizers (IM), extensive metabolizers (EM), or ultrarapid metabolizers (UM) [32]

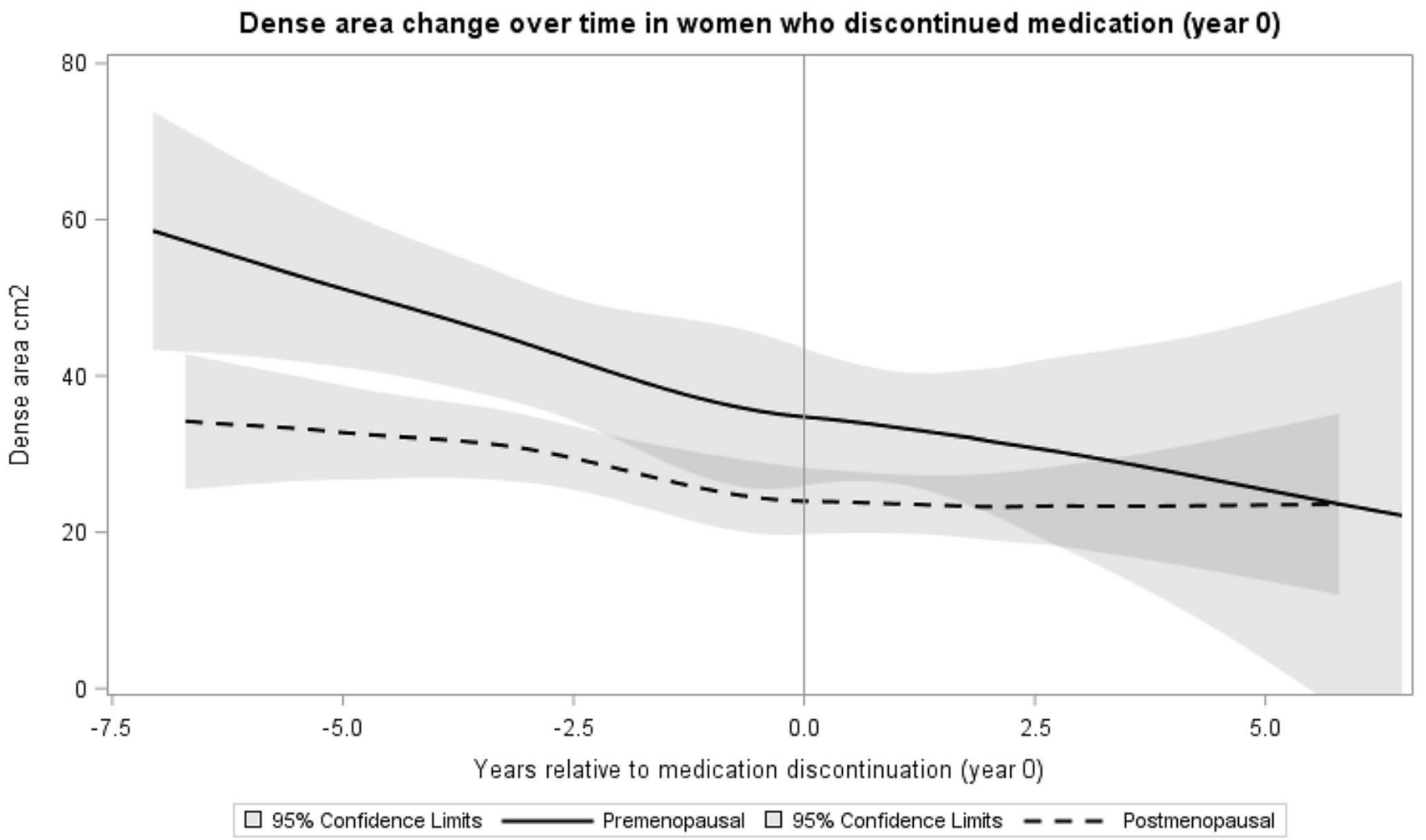

Fig. 3 Dense area change over time in patients who discontinued tamoxifen. Among women who discontinued tamoxifen, average density change was estimated for women who had their closest available mammograms between 5 years prior to discontinuation and 5 years after discontinuation ( $n=89$ patients). Time zero is the time of discontinuation. Time scale is given in years between the density measurement and tamoxifen discontinuation using discontinuation as the reference (year 0 ). The density estimates were based on non-

[39], 22 (Fig. 2). Chemotherapy frequently induces menopause in premenopausal patients and may, thus, be an important confounder for MD decrease in this group. Only a few previous studies have taken this into account. Previous data suggest that chemotherapy treatment reduces MD, especially linear b-spline regression over the 10-year interval in premenopausal $(\mathrm{N}=29)$ and postmenopausal $(\mathrm{N}=60)$ women. The fitted model was plotted with $95 \%$ confidence intervals for pre- and postmenopausal women. The premenopausal women were 51.9 (SD 4.8) years at tamoxifen discontinuation with 4.9 (SD 2.6) years of follow-up. The postmenopausal women were 67.4 years at tamoxifen discontinuation (SD 6.8) and had 3.9 years of follow-up (SD 1.8)

in younger women. As these studies have not been designed to analyze the additional impact of chemotherapy on MD in tamoxifen-treated patients, it is difficult to compare our results with previous data [18, 28, 40, 41]. In this study, no significant additional effect of chemotherapy on MD 
decrease in premenopausal women was evident. The postmenopausal group treated with chemotherapy consisted of only 17 patients and importantly, nearly 50\% (8/17) had been diagnosed with breast cancer within a year after menopause, suggesting a not completely extinguished ovarian function as a likely explanation for the pronounced density decrease observed in this subgroup.

Only one previous study has investigated the impact of goserelin on MD decrease in tamoxifen-treated breast cancer patients [42]. In contrast to this small report we did not find an association between ovarian suppression and MD decrease. The number of patients in our study treated with goserelin was, however, limited and whether tamoxifeninduced density reduction might be enhanced by ovarian suppression needs to be further studied in a larger cohort. In line with previous data, no effect on density was found in patients changing their endocrine treatment from tamoxifen to aromatase inhibitors [22, 28, 43].

Compliance to tamoxifen is an important clinical concern. A Swedish register study found that $31 \%$ of patients prescribed adjuvant endocrine treatment were non-adherent after three years [44], another that 50\% discontinued their endocrine treatment before five years treatment [45]. In our study, $7 \%$ of the patients discontinued tamoxifen within the first year and 27\% before completing 5 years of treatment. Only a few studies have investigated tamoxifen adherence and MD change and results have been inconsistent [16], 19, 28.

Interestingly, we did not detect an increase in MD after stopping tamoxifen, neither in the pre- nor in the postmenopausal patients. Although the number of patients for whom data on MD change after tamoxifen discontinuation was limited, our results suggest that in women with a MD reduction, MD does not revert to baseline levels after tamoxifen intake ends. The MD decline seemed to plateau for the postmenopausal patients after tamoxifen discontinuation, and we cannot conclude that the MD decline would have continued if tamoxifen therapy had not stopped. Agerelated declines may also occur upon tamoxifen discontinuation, especially in the premenopausal patients, as they approached menopause. The majority of the premenopausal patients at diagnosis were likely close to menopause at the time of tamoxifen discontinuation. Further assessment of MD change after tamoxifen treatment, especially in younger women is warranted.

No effect of predicted CYP2D6 activity on density decrease could be confirmed in this study. We did observe what appears to be a borderline significant trend of density reduction with higher CYP2D6 activity scores among postmenopausal women who received tamoxifen only and for all women who also received chemotherapy. Our results indicate that CYP2D6 activity does not substantially modify MD response in patients receiving multimodality adjuvant treatment. An association between CYP2D6 genotype and mammographic density change under tamoxifen treatment might be more difficult to prove in patients receiving complex adjuvant therapy. Larger sample sizes might be needed. The biological basis of the tamoxifen-dependent reduction of MD is not yet fully clarified and other factors than CYP2D6 status are also likely of importance.

Strengths of this study include the prospective collection of consecutive unselected breast cancer cases and detailed clinical data generated from individual medical records including additional adjuvant treatment and compliance to tamoxifen. CYP2D6 was extensively genotyped on DNA from blood. By using only digital images and the STRATUS system, measurement variability in MD change was reduced [29]. One limitation is our study cohort size, where $44 \%$ of the patients of the original full cohort had to be excluded, mainly due to the unavailability of digital mammograms. Digitalization of mammograms in Stockholm was initiated in 2006 but not complete until 2010, which explains the majority of missing images. No significant differences were, however, found between the study base and the full cohort regarding factors most relevant to mammographic density change. Other limitations include incomplete information on concomitant medication with CYP2D6 inhibitors and information on adherence from medical records only. Therefore, the true figure for adherence to tamoxifen might be lower. Although an association between CYP2D6 genotype and mammographic density change under tamoxifen treatment might be more difficult to demonstrate in patients receiving complex adjuvant therapy, it is altogether a strength that our study reflects modern clinical practice.

In summary, in our cohort of tamoxifen-treated breast cancer patients, other systemic adjuvant therapy does not appear to further reduce MD. Moreover, no rebound effect on MD decline after early tamoxifen discontinuation was evident. An effect of CYP2D6 activity on density decrease was not possible to confirm in the present material, with patients receiving multimodality adjuvant treatment. Future studies with larger cohorts and with consideration of adherence are warranted. More work is also needed to clarify whether critical plasma concentrations of active tamoxifen metabolites are required for MD decline under tamoxifen treatment and whether patients with no MD change on tamoxifen would benefit from switching endocrine therapy.

Supplementary Information The online version contains supplementary material available at https://doi.org/10.1007/s10549-021-06386-2.

Acknowledgements We thank Professor Espen Molden and Marianne Kristiansen Kringen at the Center for Psychopharmacology, Diakonhjemmet Hospital, Oslo, Norway for their help with CYP2D6 genotyping the patients in this study. Susanne Agartz in Professor Jonas 
Bergh's research group was helpful in retrieving the biobanked samples. The authors also thank all the patients who contributed to the study.

Author contributions Concept and study design: LT, SM, PH, ME, EE, and J.D.L. LT and ME collected and assembled the data. All authors provided contributions to data analysis and/or interpretation of results. Manuscript writing: all authors. All authors read and approved the final manuscript. SM and JB provided financial support.

Funding Open access funding provided by Karolinska Institute. SM received grants from The Cancer Society in Stockholm, Percy Falk's Foundation for research on Prostate Cancer and Breast Cancer, and The Swedish Breast Cancer Association. In addition, SM received grants from the Stockholm County Council (ALF20180419) and EE received grants from CIMED, the Stockholm County Council (ALF20190536). The study was also supported by grants from Jonas Bergh's research group which is supported by grants from the Swedish Cancer Society (19 0292 PJ 01 H and 190189 USO1 H), The Research Funds at Radiumhemmet (164003), Karolinska Institutet, Stockholm County Council (ALF2017-1341), FOU (Karolinska University Hospital account number 907515 ).

Data availability The data that support the findings of this study are available from the corresponding author upon reasonable request.

Code availability The code that support the analyses of this study are available from the corresponding author upon reasonable request.

\section{Declarations}

Conflict of interest The authors declare no conflicts of interest.

Ethical approval Approval of the study was given by the ethical review board at Karolinska Institutet (Stockholm, Sweden Dnr 2014/427-31 and 2018/2644-32).

Consent to participate Informed consent was obtained from all included patients with biobanked DNA. However, according to our ethical approval, we did not approach the patients again for this specific study.

\section{Consent for publication Not applicable.}

Open Access This article is licensed under a Creative Commons Attribution 4.0 International License, which permits use, sharing, adaptation, distribution and reproduction in any medium or format, as long as you give appropriate credit to the original author(s) and the source, provide a link to the Creative Commons licence, and indicate if changes were made. The images or other third party material in this article are included in the article's Creative Commons licence, unless indicated otherwise in a credit line to the material. If material is not included in the article's Creative Commons licence and your intended use is not permitted by statutory regulation or exceeds the permitted use, you will need to obtain permission directly from the copyright holder. To view a copy of this licence, visit http://creativecommons.org/licenses/by/4.0/.

\section{References}

1. (2005) Effects of chemotherapy and hormonal therapy for early breast cancer on recurrence and 15-year survival: an overview of the randomised trials. Lancet (London, England) 365 (9472):1687-1717. https://doi.org/10.1016/s0140-6736(05) 66544-0

2. Davies C, Pan H, Godwin J, Gray R, Arr Davies IR. Raina V, Abraham M, Medeiros Alencar VH, Badran A, Bonfill X, Bradbury J, Clarke M, Collins R, Davis SR, Delmestri A, Forbes JF, Haddad P, Hou MF, Inbar M, Khaled H, Kielanowska J, Kwan WH, Mathew BS, Mittra I, Muller B, Nicolucci A, Peralta O, Pernas F, Petruzelka L, Pienkowski T, Radhika R, Rajan B, Rubach MT, Tort S, Urrutia G, Valentini M, Wang Y, Peto R (2013) Longterm effects of continuing adjuvant tamoxifen to 10 years versus stopping at 5 years after diagnosis of oestrogen receptor-positive breast cancer: ATLAS, a randomised trial. Lancet (London, England) 381 (9869):805-816. https://doi.org/10.1016/s01406736(12)61963-1

3. Pan H, Gray R, Braybrooke J, Davies C, Taylor C, McGale P, Peto R, Pritchard KI, Bergh J, Dowsett M, Hayes DF, Ebctcg (2017) 20-year risks of breast-cancer recurrence after stopping endocrine therapy at 5 years. N Engl J Med 377(19):1836-1846. https://doi.org/10.1056/NEJMoa1701830

4. Jordan VC (2003) Tamoxifen: a most unlikely pioneering medicine. Nat Rev Drug Discov 2(3):205-213. https://doi.org/10. $1038 /$ nrd 1031

5. Desta Z (2004) Comprehensive evaluation of tamoxifen sequential biotransformation by the human cytochrome P450 system in vitro: prominent roles for CYP3A and CYP2D6. J Pharmacol Exp Ther 310(3):1062-1075. https://doi.org/10.1124/jpet.104. 065607

6. Sim SC, Ingelman-Sundberg M (2013) Update on allele nomenclature for human cytochromes $\mathrm{P} 450$ and the human cytochrome P450 allele (CYP-allele) nomenclature database. Methods Mol Biol 987:251-259. https://doi.org/10.1007/978-1-62703-321-3_ 21

7. Caudle KE, Sangkuhl K, Whirl-Carrillo M, Swen JJ, Haidar CE, Klein TE, Gammal RS, Relling MV, Scott SA, Hertz DL, Guchelaar HJ, Gaedigk A (2020) Standardizing CYP2D6 Genotype to Phenotype Translation: Consensus Recommendations from the Clinical Pharmacogenetics Implementation Consortium and Dutch Pharmacogenetics Working Group. Clin Transl Sci 13(1):116-124. https://doi.org/10.1111/cts.12692. Epub 2019 Oct 24. PMID: 31647186; PMCID: PMC6951851.

8. Gaedigk A, Sangkuhl K, Whirl-Carrillo M, Klein T, Leeder JS (2017) Prediction of CYP2D6 phenotype from genotype across world populations. Genet Med 19(1):69-76. https://doi.org/10. 1038/gim.2016.80

9. Margolin S, Lindh JD, Thoren L, Xie H, Koukel L, Dahl ML, Eliasson E (2013) CYP2D6 and adjuvant tamoxifen: possible differences of outcome in pre- and post-menopausal patients. Pharmacogenomics 14(6):613-622. https://doi.org/10.2217/pgs.13.47

10. Goetz MP, Suman VJ, Hoskin TL, Gnant M, Filipits M, Safgren SL, Kuffel M, Jakesz R, Rudas M, Greil R, Dietze O, Lang A, Offner F, Reynolds CA, Weinshilboum RM, Ames MM, Ingle JN (2013) CYP2D6 metabolism and patient outcome in the Austrian Breast and Colorectal Cancer Study Group trial (ABCSG) 8. Clin Cancer Res 19(2):500-507. https://doi.org/10.1158/1078-0432. CCR-12-2153

11. Kiyotani K, Mushiroda T, Imamura CK, Hosono N, Tsunoda T, Kubo M, Tanigawara Y, Flockhart DA, Desta Z, Skaar TC, Aki F, Hirata K, Takatsuka Y, Okazaki M, Ohsumi S, Yamakawa T, Sasa M, Nakamura Y, Zembutsu H (2010) Significant effect of polymorphisms in CYP2D6 and ABCC2 on clinical outcomes 
of adjuvant tamoxifen therapy for breast cancer patients. J Clin Oncol 28(8):1287-1293. https://doi.org/10.1200/jco.2009.25.7246

12. Schroth WGM, Hamann U et al (2009) Association between CYP2D6 polymorphisms and outcomes among women with early stage breast cancer treated with tamoxifen. JAMA 302(13):14291436. https://doi.org/10.1001/jama.2009.1420

13. Regan MM, Leyland-Jones B, Bouzyk M, Pagani O, Tang W, Kammler R, Dell'orto P, Biasi MO, Thurlimann B, Lyng MB, Ditzel HJ, Neven P, Debled M, Maibach R, Price KN, Gelber RD, Coates AS, Goldhirsch A, Rae JM, Viale G, Breast International Group 1-98 Collaborative G (2012) CYP2D6 genotype and tamoxifen response in postmenopausal women with endocrineresponsive breast cancer: the breast international group 1-98 trial. J Natl Cancer Inst 104 (6):441-451. https://doi.org/10.1093/jnci/ djs 125

14. Rae JM, Drury S, Hayes DF, Stearns V, Thibert JN, Haynes BP, Salter J, Sestak I, Cuzick J, Dowsett M, trialists A (2012) CYP2D6 and UGT2B7 genotype and risk of recurrence in tamoxifen-treated breast cancer patients. J Natl Cancer Inst 104 (6):452-460. https:// doi.org/10.1093/jnci/djs126

15. Province MA, Goetz MP, Brauch H, Flockhart DA, Hebert JM, Whaley R, Suman VJ, Schroth W, Winter S, Zembutsu H, Mushiroda T, Newman WG, Lee MT, Ambrosone CB, Beckmann MW, Choi JY, Dieudonne AS, Fasching PA, Ferraldeschi R, Gong L, Haschke-Becher E, Howell A, Jordan LB, Hamann U, Kiyotani K, Krippl P, Lambrechts D, Latif A, Langsenlehner U, Lorizio W, Neven P, Nguyen AT, Park BW, Purdie CA, Quinlan P, Renner W, Schmidt M, Schwab M, Shin JG, Stingl JC, Wegman P, Wingren S, Wu AH, Ziv E, Zirpoli G, Thompson AM, Jordan VC, Nakamura Y, Altman RB, Ames MM, Weinshilboum RM, Eichelbaum M, Ingle JN, Klein TE, International Tamoxifen Pharmacogenomics C (2014) CYP2D6 genotype and adjuvant tamoxifen: meta-analysis of heterogeneous study populations. Clin Pharmacol Ther 95(2):216-227. https://doi.org/10. 1038/clpt.2013.186

16. Nyante SJ, Sherman ME, Pfeiffer RM, Berrington de Gonzalez A, Brinton LA, Bowles EJ, Hoover RN, Glass A, Gierach GL (2016) Longitudinal change in mammographic density among ERpositive breast cancer patients using tamoxifen. Cancer Epidemiol Biomarkers Prevent 25(1):212-216. https://doi.org/10.1158/10559965.epi-15-0412

17. Mullooly M, Pfeiffer RM, Nyante SJ, Heckman-Stoddard BM, Perloff M, Jatoi I, Brinton LA, Aiello Bowles EJ, Hoover RN, Glass A, Berrington de Gonzalez A, Sherman ME, Gierach GL (2016) Mammographic density as a biosensor of tamoxifen effectiveness in adjuvant endocrine treatment of breast cancer: opportunities and implications. J Clin Oncol 34(18):2093-2097

18. Kim J, Han W, Moon HG, Ahn S, Shin HC, You JM, Han SW, Im SA, Kim TY, Koo H, Chang J, Cho N, Moon W, Noh DY (2012) Breast density change as a predictive surrogate for response to adjuvant endocrine therapy in hormone receptor positive breast cancer. Breast Cancer Res 14(4):R102. https://doi.org/10.1186/ bcr3221

19. Kim WH, Cho N, Kim YS, Yi A (2018) Mammographic density changes following discontinuation of tamoxifen in premenopausal women with oestrogen receptor-positive breast cancer. Eur Radiol. https://doi.org/10.1007/s00330-017-5293-y

20. Huo CW, Chew GL, Britt KL, Ingman WV, Henderson MA, Hopper JL, Thompson EW (2014) Mammographic density-a review on the current understanding of its association with breast cancer. Breast Cancer Res Treat 144(3):479-502. https://doi.org/10.1007/ s10549-014-2901-2

21. Li J, Humphreys K, Eriksson L, Edgren G, Czene K, Hall P (2013) Mammographic density reduction is a prognostic marker of response to adjuvant tamoxifen therapy in postmenopausal patients with breast cancer. J Clin Oncol 31(18):2249-2256. https://doi.org/10.1200/JCO.2012.44.5015

22. Shawky MS, Martin H, Hugo HJ, Lloyd T, Britt KL, Redfern A, Thompson EW (2017) Mammographic density: a potential monitoring biomarker for adjuvant and preventative breast cancer endocrine therapies. Oncotarget 8(3):5578-5559

23. Mullooly M, Nyante SJ, Pfeiffer RM, Cora R, Butcher D, Sternberg L, Aiello Bowles EJ, Fan S, Figueroa JD, Weinmann S, Hoover RN, Brinton LA, Berrington de Gonzalez A, Glass A, Sherman ME, Gierach GL (2019) Involution of breast lobules, mammographic breast density and prognosis among tamoxifentreated estrogen receptor-positive breast cancer patients. J Clin Med. https://doi.org/10.3390/jcm8111868

24. Li J, Czene K, Brauch H, Schroth W, Saladores P, Li Y, Humphreys K, Hall P (2013) Association of CYP2D6 metabolizer status with mammographic density change in response to tamoxifen treatment. Breast Cancer Res 15(5):R93. https://doi.org/10.1186/ bcr3495

25. (2012) Comparisons between different polychemotherapy regimens for early breast cancer: meta-analyses of long-term outcome among 100000 women in 123 randomised trials. The Lancet 379(9814):432-444. https://doi.org/10.1016/s0140-6736(11) $61625-5$

26. (2015) Aromatase inhibitors versus tamoxifen in early breast cancer: patient-level meta-analysis of the randomised trials. The Lancet 386(10001):1341-1352. https://doi.org/10.1016/s01406736(15)61074-1

27. Francis PA, Pagani O, Fleming GF, Walley BA, Colleoni M, Lang I, Gomez HL, Tondini C, Ciruelos E, Burstein HJ, Bonnefoi HR, Bellet M, Martino S, Geyer CE Jr, Goetz MP, Stearns V, Pinotti G, Puglisi F, Spazzapan S, Climent MA, Pavesi L, Ruhstaller T, Davidson NE, Coleman R, Debled M, Buchholz S, Ingle JN, Winer EP, Maibach R, Rabaglio-Poretti M, Ruepp B, Di Leo A, Coates AS, Gelber RD, Goldhirsch A, Regan MM (2018) Tailoring adjuvant endocrine therapy for premenopausal breast cancer. N Engl J Med 379(2):122-137. https://doi.org/10.1056/NEJMo a1803164

28. Eriksson L, He W, Eriksson M, Humphreys K, Bergh J, Hall P, Czene K (2018) Adjuvant therapy and mammographic density changes in women with breast cancer. JNCI Cancer Spectr 2(4):pky071. https://doi.org/10.1093/jncics/pky071

29. Eriksson M, Li J, Leifland K, Czene K, Hall P (2018) A comprehensive tool for measuring mammographic density changes over time. Breast Cancer Res Treat. https://doi.org/10.1007/ s10549-018-4690-5

30. Maskarinec G, Nagata C, Shimizu H, Kashiki Y (2002) Comparison of mammographic densities and their determinants in women from Japan and Hawaii. Int J Cancer 102(1):29-33. https://doi.org/ 10.1002/ijc. 10673

31. Haars G vNP, van Gils CH, Grobbee DE, Peeters PH (2005) Measurements of breast density: no ratio for a ratio. Cancer Epidemiol Biomarkers Prev 14:2634-2640. https://doi.org/10.1158/10559965.EPI-04-0824

32. Goetz MP, Sangkuhl K, Guchelaar HJ, Schwab M, Province M, Whirl-Carrillo M, Symmans WF, McLeod HL, Ratain MJ, Zembutsu H, Gaedigk A, van Schaik RH, Ingle JN, Caudle KE, Klein TE (2018) Clinical pharmacogenetics implementation consortium (CPIC) guideline for CYP2D6 and tamoxifen therapy. Clin Pharmacol Ther 103(5):770-777. https://doi.org/10.1002/cpt.1007

33. Thoren L, Lindh JD, Ackehed G, Kringen MK, Hall P, Bergh J, Molden E, Margolin S, Eliasson E (2021) Impairment of endoxifen formation in tamoxifen-treated premenopausal breast cancer patients carrying reduced-function CYP2D6 alleles. Br J Clin Pharmacol 87(3):1243-1252. https://doi.org/10.1111/bcp.14500

34. Cleveland WS (1979) Robust locally-weighted regression and smoothing scatterplots. J Am Stat Assoc 74:829-836 
35. Eriksson M EM, Borgquist S, Hellgren R, Margolin S, Thoren L, Rosendahl A, Lång K,Tapia J, Bäcklund M, Discacciati A, Crippa A, Gabrielson M, Hammarström M, Wengström Y, Czene, K, Hall P (2021) Low dose tamoxifen for mammographic density reduction - a randomized controlled trial. J Clin Oncol

36. Eilers PHC, Marx BD (1996) Flexible Smoothing with $B$-Splines and Penalties. Stat Sci 11:89-121

37. McCormack VA, dos Santos SI (2006) Breast density and parenchymal patterns as markers of breast cancer risk: a meta-analysis. Cancer Epidemiol Biomarkers Prevent 15(6):1159-1169. https:// doi.org/10.1158/1055-9965.EPI-06-0034

38. Nyante SJ, Sherman ME, Pfeiffer RM, Berrington de Gonzalez A, Brinton LA, Aiello Bowles EJ, Hoover RN, Glass A, Gierach GL (2015) Prognostic significance of mammographic density change after initiation of tamoxifen for ER-positive breast cancer. J Natl Cancer Inst. https://doi.org/10.1093/jnci/dju425

39. Engmann NJ, Scott CG, Jensen MR, Ma L, Brandt KR, Mahmoudzadeh AP, Malkov S, Whaley DH, Hruska CB, Wu FF, Winham SJ, Miglioretti DL, Norman AD, Heine JJ, Shepherd J, Pankratz VS, Vachon CM, Kerlikowske K (2017) Longitudinal changes in volumetric breast density with tamoxifen and aromatase inhibitors. Cancer Epidemiol Biomarkers Prevent 26(6):930-937. https://doi.org/10.1158/1055-9965.epi-16-0882

40. Sandberg ME, Li J, Hall P, Hartman M, dos-Santos-SilvaHumphreys IK, Czene K (2013) Change of mammographic density predicts the risk of contralateral breast cancer-a case-control study. Breast Cancer Res 15(4):R57. https://doi.org/10.1186/bcr3451

41. Knight JA, Blackmore KM, Fan J, Malone KE, John EM, Lynch CF, Vachon CM, Bernstein L, Brooks JD, Reiner AS, Liang X, Woods M, Bernstein JL (2018) The association of mammographic density with risk of contralateral breast cancer and change in density with treatment in the WECARE study. Breast Cancer Res 20(1):23. https://doi.org/10.1186/s13058-018-0948-4

42. Yang H, Zong X, Yu Y, Shao G, Zhang L, Qian C, Bian Y, Xu X, Sun W, Meng X, Ding X, Chen D, Zou D, Xie S, Zheng Y, Zhang J, He X, Sun C, Yu X, Ni J (2013) Combined effects of goserelin and tamoxifen on estradiol level, breast density, and endometrial thickness in premenopausal and perimenopausal women with early-stage hormone receptor-positive breast cancer: a randomised controlled clinical trial. Br J Cancer 109(3):582-588. https://doi. org/10.1038/bjc.2013.324

43. Vachon CM, Suman VJ, Brandt KR, Kosel ML, Buzdar AU, Olson JE, Wu FF, Flickinger LM, Ursin G, Elliott CR, Shepherd L, Weinshilboum RM, Goss PE, Ingle JN (2013) Mammographic breast density response to aromatase inhibition. Clin Cancer Res 19(8):2144-2153. https://doi.org/10.1158/1078-0432. CCR-12-2789

44. Wigertz A, Ahlgren J, Holmqvist M, Fornander T, Adolfsson J, Lindman H, Bergkvist L, Lambe M (2012) Adherence and discontinuation of adjuvant hormonal therapy in breast cancer patients: a population-based study. Breast Cancer Res Treat 133(1):367-373. https://doi.org/10.1007/s10549-012-1961-4

45. He W, Fang F, Varnum C, Eriksson M, Hall P, Czene K (2015) Predictors of discontinuation of adjuvant hormone therapy in patients with breast cancer. J Clin Oncol 33(20):2262-2269. https://doi.org/10.1200/JCO.2014.59.3673

Publisher's Note Springer Nature remains neutral with regard to jurisdictional claims in published maps and institutional affiliations. 